International Journal of Food Science, Nutrition and Dietetics (IJFS)

ISSN 2326-3350

\title{
Determination of Maltose in Honey
}

Fujita I

Research Article

${ }^{1}$ Kumamoto Prefectural Institute of Public Health and Environmental Science, 1240-1 Kurisaki-machi, Uto-shi, Kumamoto, 869-0425, Japan.

\section{Abstract}

Honey is an excellent nutritious food and is widely produced and marketed. However, there have been complaints that some marketed honey is adulterated with maltose. We quantified glucose, fructose, maltose and sucrose contained in honey products in the marketplace, and showed that some had been adulterated.

Keywords: Honey, Sugars, High-Performance Liquid Chromatography

\section{*Corresponding Author:}

Itsusei Fujita,

Kumamoto Prefectural Institute of Public Health and Environmental Science, 1240-1 Kurisaki-machi, Uto-shi,

Kumamoto, 869-0425, Japan.

E-mail: hujita-i@pref.kumamoto.lg.jp

Received: October 18, 2012

Accepted: November 20,2012

Published: December 03, 2012

Citation: Fujita I (2012) Determination of Maltose in Honey. Int J Food Sci Nutr Diet. 1(1), 1-2. doi: http://dx.doi.org/10.19070/2326-3350120001

Copyright: Fujita $\mathbf{I}^{\mathcal{O}}$ 2012. This is an open-access article distributed under the terms of the Creative Commons Attribution License, which permits unrestricted use, distribution and reproduction in any medium, provided the original author and source are credited.

\section{Introduction}

Honey bees collect honeydew from flowers and store it in their nest, but, when they collect honeydew, they add invertase, which decomposes the honeydew, in their bodies. For this reason, the composition of honey, initially consisting primarily of sucrose, gradually changes in the nest. The nest of honeybees is always maintained at about $35^{\circ} \mathrm{C}$ due to the metabolic heat of bees and is continuously ventilated by the fanning behavior of worker drones. This promotes the evaporation of water and condenses honey to a sugar content of nearly $80 \%$.[1] It is highly nutritious as it contains isomaltooligosaccharide, gluconolactone, various vitamins, minerals, and amino acids as well as glucose and fructose, with a heat quantity of $12.307 \mathrm{~kJ}(2.94 \mathrm{kcal})$ per gram.[2] Some honey products marketed in Japan are suspected to be adulterated with maltose to increase the sweetness, and organizations such as the Consumer Affairs Bureau are requested to analyze them. $[3,4,5]$ The author investigated whether honey samples had been adulterated with maltose by quantifying their glucose, fructose, maltose, and sucrose contents using the pre-column derivatization method, which was reported previously. $[6,7]$

\section{Methods and Reagents}

\section{Reagents}

Ethyl ester of aminobenzoic acid, phosphoric acid, acetic acid, phenylhydrazine (Wako Pure Chemical Industries), and sodium cyanoborohydrate (Nakalai Tesque).

\section{Machine}

\section{Shimadzu LC20A-PAD and RF}

\section{Sample}

Commercially distributed honey products made in Japan were purchased as samples.

\section{Preparation of samples}

Exactly $0.1 \mathrm{~g}$ of honey was weighed and dissolved with $100 \mathrm{ml}$ of pure water.

\section{Derivatization of glucose and maltose}

To $5 \mathrm{ml}$ of the water solution of honey, $400 \mu \mathrm{l}$ of $1.4 \mathrm{M}$ sodium cyanoborohydrate solution in water, $400 \mu \mathrm{l}$ of acetic acid, and $2 \mathrm{~mL}$ of $0.6 \mathrm{M}$ ethyl ester aminobenzoic acid (methanol) were added, and the mixture was heated at $80^{\circ} \mathrm{C}$ for 10 minutes. After it had been cooled to room temperature, $2 \mathrm{ml}$ of distilled water was added. The water phase was washed with $4 \mathrm{ml}$ of chloroform to remove ethyl ester of aminobenzoic acid from the water phase, and the water phase was applied to HPLC.

\section{Conditions of chromatography of glucose and maltose}

Column: Cosmosil $\quad 3 \times 100 \mathrm{~mm} 3 \mu \mathrm{m}$

Mobile phase: Acetonitrile/methanol (1:1) : 0.5\% acetic acid $=3: 7$

Flow rate: $0.2 \mathrm{ml} / \mathrm{min}$

Column temperature: $45^{\circ} \mathrm{C}$

UV: $307 \mathrm{~nm}$ 


\section{Derivatization of fructose and sucrose}

To $1 \mathrm{ml}$ of the water solution of honey, $1 \mathrm{ml}$ of hydrazine solution (phosphoric acid, acetic acid, phenylhydrazine $=110: 90: 3$ ) was added. The mixture was allowed to react at $150^{\circ} \mathrm{C}$ for $10 \mathrm{~min}-$ utes, cooled to room temperature, and applied to HPLC.

\section{Chromatographic conditions of fructose and sucrose}

Column: Intersil Ph-3 4.6×150 mm 5um

Mobile phase: Acetonitrile/methanol (1:1) : water $=35: 65$

Flow rate: $1.0 \mathrm{ml} / \mathrm{min}$

Column temperature: $45^{\circ} \mathrm{C}$

Fluorescence: Excitation at $330 \mathrm{~nm}$, emission at $470 \mathrm{~nm}$

\section{Results and Discussion}

The purchase of 100 samples (honey), the sample was quanti- fied sugars arbitrarily choose the 5 samples. Table 1 shows the results of analysis of the 5 samples. Commercially distributed honey products made in Japan were purchased as samples. In 4 samples, glucose and fructose together accounted for nearly $80 \%$ of the sugar content, and no adulteration with maltose to increase the sweetness was observed. In the remaining 1 sample, maltose was detected at about $17 \mathrm{~g} / 100 \mathrm{~g}$. If sucrose had been contained, there is the possibility that its degradation into glucose and fructose had not been sufficiently advanced, but maltose was clearly an additive $[3,4,5]$. Analytical method that can be accurately quantified in the laboratory there is only a simple machine such as the Consumer Affairs Bureau, as evidenced by the previous report. Our study confirmed that maltose is added to some honey products marketed in Japan. The calibration curve of five points (UV and fluorescence) was the first regression line. As for $\mathrm{r}, 0.9999$ was obtained $(1,10,100,500$, and 1000,mg/L). This time, the method to determine the developed sugar was the fixed limit of the quantification value of $0.1 \mathrm{mg} / \mathrm{dl}$. The results of addition-recovery (honey) experiments (1,10 and $100 \mathrm{mg}$ ) of

Table 1: Quantification of sugars in honey

\begin{tabular}{|c|c|c|c|c|}
\hline & Glucose $(\mathbf{g} / \mathbf{d l})$ & Fructose $(\mathrm{g} / \mathrm{dl})$ & Maltose $(\mathrm{g} / \mathrm{dl})$ & Sucrose $(\mathrm{g} / \mathrm{dl})$ \\
\hline Honey a & $33.104 \pm 0.003$ & $35.721 \pm 0.005$ & $0.000 \pm 0.000$ & $0.000 \pm 0.000$ \\
\hline Honey b & $27.610 \pm 0.002$ & $23.881 \pm 0.006$ & $17.153 \pm 0.007$ & $0.000 \pm 0.000$ \\
\hline Honey c & $35.104 \pm 0.003$ & $33.721 \pm 0.005$ & $0.000 \pm 0.000$ & $0.000 \pm 0.000$ \\
\hline Honey d & $31.243 \pm 0.004$ & $35.412 \pm 0.001$ & $0.000 \pm 0.000$ & $0.000 \pm 0.000$ \\
\hline Honey e & $35.104 \pm 0.003$ & $33.721 \pm 0.005$ & $0.000 \pm 0.000$ & $0.000 \pm 0.000$ \\
\hline
\end{tabular}

Table 2: Recoveries of glucose fructose, maltose, and sucrose

\begin{tabular}{|c|c|c|c|}
\hline Substance & Trials & Added & Recovery (\%) \\
\hline \multirow{3}{*}{ Glucose } & \multirow{3}{*}{5} & $100 \mathrm{mg}$ & 98.5 \\
\cline { 3 - 4 } & & $10 \mathrm{mg}$ & 98.2 \\
\cline { 3 - 4 } & & $1 \mathrm{mg}$ & 99.1 \\
\hline \multirow{3}{*}{ Fructose } & \multirow{3}{*}{5} & $100 \mathrm{mg}$ & 98.3 \\
\cline { 3 - 4 } & \multirow{2}{*}{ Maltose } & $10 \mathrm{mg}$ & 97.4 \\
\cline { 3 - 4 } & \multirow{3}{*}{5} & $1 \mathrm{mg}$ & 99.2 \\
\hline \multirow{2}{*}{ Sucrose } & \multirow{2}{*}{5} & $100 \mathrm{mg}$ & 97.9 \\
\cline { 3 - 4 } & & $10 \mathrm{mg}$ & 99.6 \\
\hline & & $100 \mathrm{mg}$ & 98.9 \\
\hline & & $10 \mathrm{mg}$ & 99.1 \\
\cline { 3 - 4 } & & $1 \mathrm{mg}$ & 98.4 \\
\hline
\end{tabular}

glucose, maltose, fructose, and sucrose are shown in Table 2. The recovery rate was as high as $90 \%$. The precision of quantification was marked.

By using cheap (machinery cheaper than MS) and simple(no complicated than post-column) method[6,7] for the determination we have developed, we can prove that honey that has been sweetened of maltose is present.

\section{References}

[1]. Y. Hayashi, S. Yamashita and N. Ishikawa (1966) Studies on Natural honey J. Health Science 12 317-320

[2]. K. Aso , T. Watanabe and K. Yamao (1958) Studies on Honey(I) : On the
Sugar Composition of Honey J. Fermentation Engineering 36 39-44

[3]. K. Sato "Tenkannichijo" Japan press 2007 pp134-142

[4]. S. Mishima, N. Hiraiwa, Y. Araki(2003) Analysis of high-fructose corn syrup in honey by using post-column reaction method J Japanese Society for Food Science and Technology 50 78-84

[5]. K. Okazaki(1990) Studies on the quality of commercial honey Nutrition and Food 23 374-378

[6]. I. Fujita and T. Tobino(2011) Determination of sugars in sports drinks J. Food Technology 9 139-140

[7]. I. Fujita (2012) Determination of saccharides in sports drinks J. Nutrition and Food Science 2 121-122 